\title{
Developmental Dynamics of Interrelation between Intelligence and Achievement Motivation of Students
}

\author{
Nadezhda Zhiyenbayeva \\ Professor of Kazakh National University \\ named after Abay
}

\author{
Olga Tapalova \\ Professor of Kazakh National University \\ named after Abay
}

\begin{abstract}
Estimation of students' perspective in educational activity requires diagnostic of intelligence and its relation to the level of motivation to realize their potential and possibilities. Psychodiagnostic research was conducted in order to study developmental dynamics of changes in achievement motivation of students in process of educational activity. The research involved 181 students of the $7^{\text {th }}-8^{\text {th }}$ grades; repeated experiment (in a year) involved 181 students of the $8^{\text {th }}-9^{\text {th }}$ grades. Research revealed that students with high level of intelligence and high level of achievement motivation, reach high academic success.

Key words: educational activity motivation, cognitive motivation, achievement motivation, intelligence, developmental dynamics.
\end{abstract}

\section{Introduction}

The problem of educational activity motivation is one of the fundamental problems of psychology [1].

Motivation is a key component of educational activity. Educational activity should be organized in such way that could maximize the disclosure of internal motivational potential of student's personality [2].

Currently, there is a certain intensification of researches of achievement motivation namely in educational activity. Modern researches assert the existence of interrelation between intelligence and achievement motivation [3-7]. Research of psychological factors that act like predictors of academic performance, traditionally focus on two main groups of variables: intellectual, on the one hand, and motivational and personal, on the other [8]. Practical psychologists believe that motivation and cognition form a unified system [9-12].

By the definition of David Wechsler: "Intelligence is the aggregate or global capacity of the individual to act purposefully, to think rationally and to deal effectively with his environment" [13]. Intelligence is the basis of human's cognitive relation to the world and many scientists admit that it is a core of developing personality [14].
Achievement motivation is a variant of activity motivation expression, related primarily to the orientation of the individual to achieve success and avoid failure.

In the psychologically meaning achievement motivation is a kind of interpretive "key" to understand the nature of the aspiration level, striving to improve self-esteem, and building up the ways to make responsible decisions and regulate activities [15].

H.Heckhausen states that, according to the concept of cumulative achievement of J.Atkinson, the impact of motivation should be seen more efficiently at high rate of intelligence (IQ) [4].

H.Heckhausen also proposed a model of complementarity which predicts that there is an upper limit of the intelligence distribution, above which the achievements depend solely on differences in motivation; there is also the lower limit below which the motivation is irrelevant [4].

The purpose of this research was to study developmental dynamics of interrelation between intelligence, achievement motivation and actual cumulative achievements of the individual in educational activity.

\section{Research methods}

181 students from secondary schools participated in the experimental psychodiagnostic research of developmental dynamics of interrelation between intelligence and achievement motivation in age from 12 to 15 years. The data were collected through a longitudinal study; the first experiment involved 181 students, among them: age category of 12-13 year olds (the $7^{\text {th }}$ grades) -89 students ( 48 females and 41 males) and age category of 13-14 year olds (the $8^{\text {th }}$ grades) - 92 students (49 females and 43 males). The first experiment was conducted during the third quarter of the 2009-2010 school year.

The second part of the experiment with the same students held a year later, during the third quarter of the 2010-2011 school year. The experiment was conducted in Kyzylorda city. School administration presented data of students' physical state, information about parents, i.e. social status of each respondent. 
The method of cross sections according to the methodic of Teenage intellectual test was used to monitor the indicators of students' intelligent;

WISC - D.Wechsler Intelligence Scale for Children in the modification of U.I.Filimonenko V.I.Timofeeva was used as a diagnostic tool [16].

D.Wechsler Intelligence Scale is one of the most popular and commonly used tools to measure the structure of individual intelligence in psychological researches. The main advantage of using that method is an ability of getting complex quantitative and qualitative indicators that characterize the peculiarity of examinees' intelligence.

"Test-questionnaire to measure achievement motivation" by A.Mehrabian adapted by M.S. Magomed-Eminov was used for diagnosis of the achievement motivation intensity [17]. Testquestionnaire to measure achievement motivation intended to diagnose two generalized stable motives of personality: the motive of achieving success and the motive of avoiding failure. In this case, test estimate which of these two motives dominate. Test is a questionnaire, which has two forms - male (form A) and female (form B). The data were processed by the methods of mathematical statistics and factor analysis.

\section{Results and discussion}

At the first stage of the study we conducted psychometric measurement of intelligence of the $7^{\text {th }}$ $8^{\text {th }}$ grades students.

The main criteria for intelligence psychodiagnostic are estimation of peculiarities of intellectual and personal development. The individual test profile of examinee was obtained in the processing of test results, this profile indicates of priority mastering the concepts and logic operations and prevalence of verbal or figurative thinking.

Wechsler test is based on a hierarchical theory of intelligence, estimates the total general factor of intelligence, as well as verbal and non-verbal intelligence.

Six subtests were used to determine the verbal intelligence: "Information", "Comprehension", "Arithmetic", "Similarities", "Vocabulary" and "Number Sequencing". Nonverbal intelligence is estimated using the following six subtests: "Picture Completion", "Picture Arrangement", "Block Design", "Object Assembly", "Coding" and "Mazes" (Table 1).

\section{Table 1. Average values of the intelligence score of WISC subtests for the}

$7^{\text {th }}$ and $8^{\text {th }}$ grades students (2009-2010)

\begin{tabular}{|c|c|c|c|}
\hline & Subtest & $7^{\text {th }}$ grade & $8^{\text {th }}$ grade \\
\hline \multicolumn{4}{|c|}{ Verbal intelligence } \\
\hline 1 & Information & 18,0 & 19,7 \\
\hline 2 & Comprehension & 11,4 & 13,5 \\
\hline 3 & Arithmetic & 15,3 & 15,3 \\
\hline
\end{tabular}

\begin{tabular}{|c|c|r|c|}
\hline 4 & Similarities & 15,8 & 16,7 \\
\hline 5 & Vocabulary & 38,2 & 43,2 \\
\hline 6 & Number sequencing & 12,4 & 15,7 \\
\hline \multicolumn{3}{|c|}{ Nonverbal intelligence } \\
\hline 7 & Picture completion & 13,8 & 15,6 \\
\hline 8 & Picture arrangement & 39,7 & 36,6 \\
\hline 9 & Block design & 42,5 & 45,7 \\
\hline 10 & Object assembly & 23,9 & 25,8 \\
\hline 11 & Coding & 53,7 & 57,9 \\
\hline 12 & Mazes & 16,8 & 17,9 \\
\hline
\end{tabular}

Testing groups of the $7^{\text {th }}$ and $8^{\text {th }}$ grades using WISC subtests identifies age peculiarities of intelligence that are specific to adolescents of this age. These peculiarities include analyticity and great susceptibility to the influence of education. Analysis of "Vocabulary" subtest's results shows that the indicators of the $8^{\text {th }}$ grade students are higher than indicators of the $7^{\text {th }}$; this is also confirmed by high marks of most students. Score of "Similarities" subtest shows a slight difference in the results, which is probably due to the cultural and educational situation of modern students development. In contrast to the 7 th grade, majority of the $8^{\text {th }}$ grade students gave logically sound answers. Students of the $7^{\text {th }}$ and $8^{\text {th }}$ grades showed low results in the following subtests: "Information", “Comprehension”, “Arithmetic”, "Mazes” (Figure1).

Table 2 shows the results of testing on WISC subtests (total IQ), that show the overall picture of average values of the intelligence score of students at the beginning of the experiment.

Table 2. Testing scores of WISC (total IQ) for experimental grades students

\begin{tabular}{|l|c|c|}
\hline \multicolumn{1}{|c|}{ Grade } & $7^{\text {th }}$ grade & $8^{\text {th }}$ grade \\
\hline Average value & 116 & 112 \\
\hline Min & 90 & 85 \\
\hline Max & 150 & 148 \\
\hline Standard deviation & 12,7 & 13,8 \\
\hline Standard error & 1,8 & 1,9 \\
\hline Asymmetry & 0,65 & $-0,03$ \\
\hline Excess & 0,15 & $-0,15$ \\
\hline
\end{tabular}

Overall, the indicators of intelligence are uneven: a small number of examinees have a high level (IQ), majority has an average rate. After reviewing the academic grades and academic achievements of each examinee, we found that those with high intelligence level (IQ) have low academic performance. Such students have very low academic grades in mathematics and natural science disciplines. And also in the process of interviewing children, we noted that many of them show unwillingness to express their thoughts.

Data obtained during the study led us to the idea of prevalence of low achievement motivation of examinees, we hypothesized that the educational success depends on general intelligence jointly with goals, interests and motivation.

Correlation between educational success and levels of general or verbal intelligence usually range from 0.19 to 0.60 [18]. 


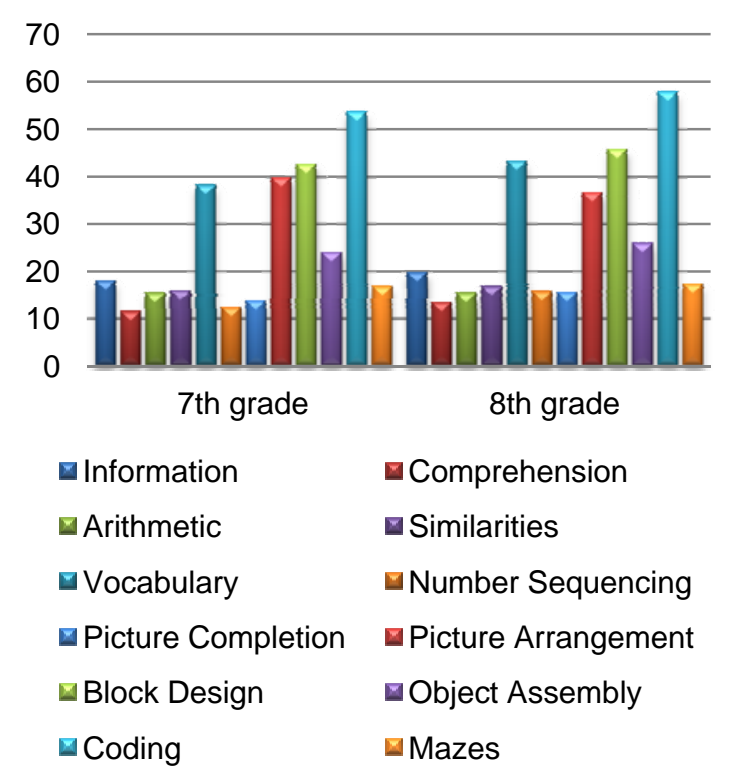

Figure 1. Comparative diagram of average values of WISC subtests

L.F.Burlachuk and V.M.Bleicher indicate that students with high rate of mental development also fall into the category of academically weak students. One of the fundamental reasons for that is the lack of motivation to learn. However, people with intelligence level lower than average, never enter a number of academically well students. The main reason of low educational performance of children with a high IQ was the lack of educational motivation [19].

The next stage of our experimental study required identification of types and levels of examinees' achievement motivation. Students were tested for "Test-questionnaire to measure achievement motivation", testing procedure was carried out individually, during a single session. Runtime of test by A.Mehrabian was 25 minutes. The data obtained by Mehrabian's questionnaire after processing looked as follows: calculation of total score for each examinee and their ranking.

The test results of the 7 th grades students are: "High level" $-10 \%$ of surveyed were characterized by motive of achieving success "Low level" - $20 \%$ of surveyed guide by motive of avoiding failure, "Average level" $-70 \%$ of surveyed showed average rate of achievement motivation.

The test results of the 8th grades students are: "High level" $-18 \%$ of surveyed were characterized by motive of achieving success, "Low level" - 19\% of surveyed guide by motive of avoiding failure, "Average level" $-63 \%$ of surveyed showed average rate of achievement motivation.

Figures 2 and 3 show the initial data of achievement motivation levels for the age groups of surveyed.

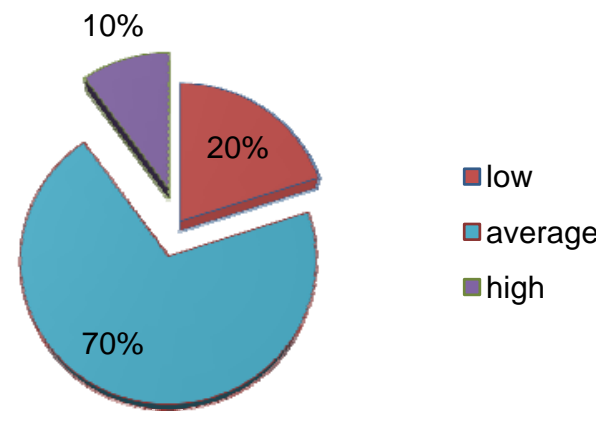

Figure 2. Achievement motivation levels of the $7^{\text {th }}$ grade before training

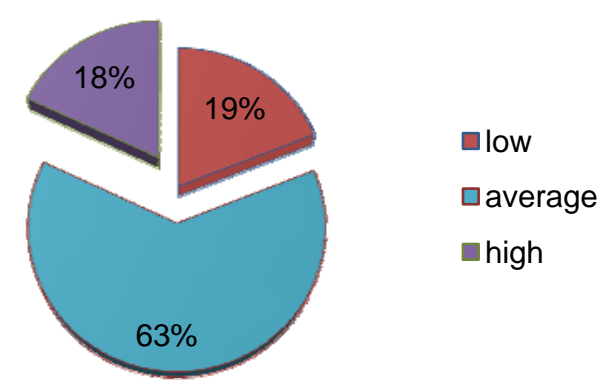

Figure 3. Achievement motivation levels of the $8^{\text {th }}$ grade before training

The results of experiment on determination of achievement motivation and avoiding failures confirm the scatter of achievement motivation and inconsistency with the indicators of levels of general intelligence. Evidently specificity of pubertal period prevents the possibility of finding balance between intellectual abilities and achievement motivation. Teenager "wants a lot, but does little for that", he overestimates and underestimates own capabilities.

The obtained data on the state of intellectual abilities and levels of students' achievement motivations led us to the decision of conduction psychological training to improve achievement motivation. This training allows us to prove that intelligence determines learning effectiveness only if it correlates with high achievement motivation.

The purpose of psychological training was to achieve a persistent increase of the level of achieving success motivation and reduce the level of avoiding failure motivation.

Aims of the training:

1. Form student's persistent willingness and ability of self-setting goals at the end of the training.

2. Develop students' high striving to achieve selfset goals.

Training object: students of the experimental 7th and 8 th grades. 
Training duration was 10 days including 5 days with the students of the 7 th grades and 5 days with the 8 th grades students.

Methods of achievement motivation forming consisted of the following: During the training, the participants were given the stimulus material: categories of content of projective stories, reflecting the motivation to achieve and avoidance, pictures with the theme of achievements. Material representing the situation of training was also given: lists of categories and characteristics peculiar to motivation of success achievement, and exercises for self-fulfillment.

Work of psychological training was built according to the presence of formative influences of D.McClelland [20]. This training program includes the use of all formative influences.

We developed a variety of tutorials for the achievement motivation training (training videos, projective stories, special games, booklets with themed stories, etc.).

Students were taught ways of behavior typical to a person with a high achievement motivation. Concrete examples from their daily life, and the life of people with a high achievement motivation were reviewed during the training. To make projective stories with a strong theme of achievements: the participants were given a list of categories of achievement motivation that they had to use in the story. After 10 minutes, each of participants read his story and the experimenter briefly analyzed and expressed praise and approval. Student instantly felt the results of high achievement, and received a positive emotional state associated with the work, achievement and success in the implementation of this goal.

At the end of the training we reviewed the independent behavior of participants in accordance with the acquisition motive against the lack of support and control of the experimenter. At this stage, there were no elements of the analysis: the experimenter offered to play this or that situation, and those present participated in a form in which they are wanted.

We carried out special psychological training with the participants during the fourth quarter, and then holiday period came. Before the summer break, students received a large number of assignments (mostly reading of a certain literature, tips on trips, tips to conduct surveillance of certain life situations).

Motivational training was very effective in improving the academic success of students. The effect of achievement motivation training spread to extracurricular activities of students i.e. attitude to the use of free time became more appropriate and promising.

During the second stage of the research (20102011) with the already proven methods some changes in the levels of achievement motivation were identified at students of the experimental grades that have moved to the next grade.

Figures 4 and 5 show levels of achievement motivation that were formed after psychological training.

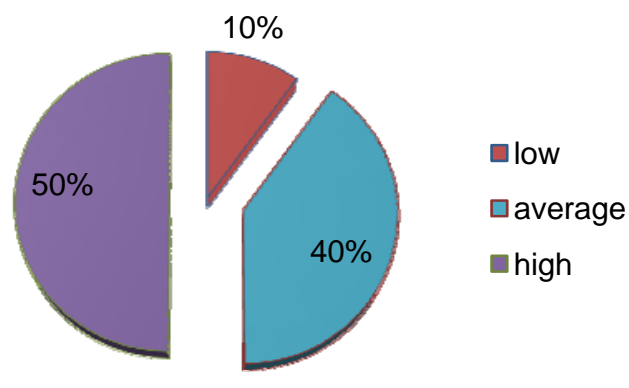

\section{Figure 4. Achievement motivation levels of the $8^{\text {th }}$ grade after training}

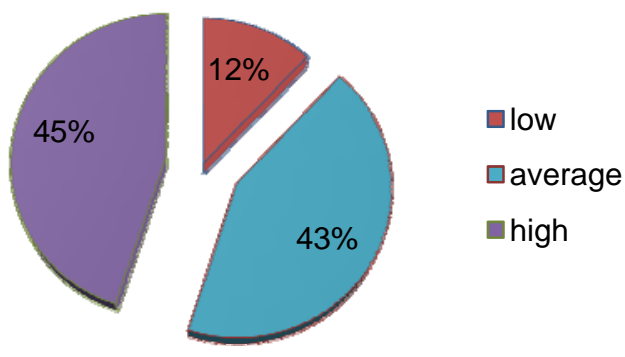

\section{Figure 5. Achievement motivation levels of the $9^{\text {th }}$ grade after training}

The results of the 8th grade are following: "High level" - $50 \%$ of surveyed were characterized by motive of achieving success, "Low level" decreased to $10 \%$ of surveyed guide by motive of avoiding failure, "Average level" - indicator of this level decreased to $40 \%$.

The results of the 9th grade are following: "High level" - $45 \%$ of surveyed were characterized by motive of achieving success, "Low level" - only $12 \%$ of surveyed guide by motive of avoiding failure, "Average level" - indicator of this level remained at the same mark of $43 \%$.

Academic achievements of students after the training have increased significantly this proves that the achievement motivation during adolescence is primarily responsible for the development of the intellectual abilities of students.

At the second stage of the study we also conducted the same determination of gender differences in intelligence and achievement motivation (Table 3 ).

These data demonstrate that the females achievement motivation is related to the level of 
psychometric intelligence, and for males, these parameters are inversely related.

The data on gender differences in psychometric intelligence and achievement motivation are also distributed across age groups.

Table 3. Average values of gender differences in intelligence and achievement motivation $\left({ }^{*} \mathbf{p}<0.05\right)$

\begin{tabular}{|c|c|c|c|c|}
\hline $\begin{array}{c}\text { Age } \\
\text { group }\end{array}$ & \multicolumn{2}{|c|}{$\begin{array}{c}\text { Average values of } \\
\text { achievement } \\
\text { motivation }\end{array}$} & \multicolumn{2}{|c|}{$\begin{array}{c}\text { Average values } \\
\text { of intelligence }\end{array}$} \\
\hline & female & male & female & male \\
\hline $8^{\text {th }}$ grade & 112,5 & 122,1 & 91,68 & 105,2 \\
\hline $9^{\text {th }}$ grade & $122,67^{*}$ & $148,5^{*}$ & 98,43 & 93,5 \\
\hline
\end{tabular}

Table 3 shows that in 14-15 years, the differences between males and females at the average values of intelligence and achievement motivation reduce, but in average males have higher IQ than females $(\mathrm{p}<$ $0.05)$. At the age of 15 the males outperform females in achievement motivation indicators $(\mathrm{p}<0.05)$. There is a tendency of correlation increase between psychometric intelligence and achievement motivation.

\section{Conclusion}

Thus, summing up this research of achievement motivation and intelligence we can point out the following. Developmental (age) dynamics of intelligence and achievement motivation indicators is uneven. At the age of 12 to 15 years there is a few "downs" and "ups" in the development of intelligence and achievement motivation. Period, we have taken for the experiment corresponds to adolescence, when the ratio of average intelligence and academic achievement indicators does not match.

The results obtained in the longitudinal study of the dynamics of interrelation between intelligence and achievement motivation shows the contradictory of intellectual development and reducing indicators of intellectual productivity. Research revealed that in this age the integrity of the intelligence is unsustainable.

In our opinion, during this age period it is necessary to pay attention to the integrity of the student's psyche, as puberty is the peak of the adolescent crisis. One of coping mechanisms for this crisis is the close attention and monitoring of student's mental development by parents, teachers and psychologists.

Thus, during our research, the need of study the mechanisms of intellectual development of adolescent in relation to achievement motivation for predicting academic success is being confirmed.

The results of this research show that timely conducting of special psychological trainings in achievement motivation improvement are necessary in the age of 13-15, since this age is a sensitive period of intelligent system development, which is characterized by the formation of a global integrity intellect that contains significant potential for further development.

\section{References}

[1] Feldstein, D.I., Development of fundamental psychological researches, MODEK, Moscow, 2006.

[2] B.A. Weiner, "Theory of motivation for some classroom experiences", Journal of Educational Psychology, 1979, pp.2-3.

[3] Heckhausen, H., Motivation and Action 2nd Edition, Pedagogika, Moscow, 1986

[4] Heckhausen, H., Psychology of achievement motivation, Rech, St. Petersburg, 2001

[5] Atkinson, J.W., Lens, W., O'Malley, P.M. Motivation and ability: interactive psychologic determinants of intellective performance, educational achievement, and each other, Academic Press, New York, 1978.

[6] T.Gjesme "Motive to achieve success and motive to avoid failure in relation to school performance for pupils of different ability levels", II Scandinavian Journal of Educational Research, 1971, pp.91-99.

[7] Atkinson, J.W., Raynor, J.O., Strength of motivation and efficiency of performance, Motivation and Achievement, Washington, D.C., 1974.

[8] T.O. Gordeeva, E.N.Osin, "Differences in achievement motivation and learning motivation in students exhibiting different types of academic attainment (Unified State Examination (USE) scores, academic competition results, academic records)", Psichologicheskie issledovaniya, Moscow, 2012, pp.5.

[9] E.V.Vorobeva, V.N.Druzhinin, "Identification of the mismatch between general cognitive ability and achievement motivation", Psychologicheskii Mezhvuzovskii Vestnik, RAN, Moscow, 1997, pp.120-127. [10] Zhiyenbayeva, N.B. The development of the individual activity of modern young pupil in the process of building communication, KazNPU Press, Almaty, 2008

[11] Zanuk, S.S., Psychology of motivation. Theory and practice of motivation, Nika center, Kiev, 2001.

[12] S.B.Malyh, E.D.Gindina, "The nature of individual characteristics of temperament in adolescence", Psychologicheskii journal, 2004, pp. 29-52.

[13] Pozina, M.B., Psychology and Pedagogics, University of Natalya Nesterova, Moscow, 2001.

[14] O.S.Chalikov, "Interrelation of intellectual development of adolescents with school academic performance", Psychologicheskii Vestnik Uralskogo universiteta, Yekaterinburg, 2001.

[15] Kondratev, M.U., Iliin, V.A., ABCs of social psychologist practice, PER-SE, Moscow, 2007.

[16] Filimonenko, U.I., Timofeeva, V.I., Guidance to the Wechsler's scale of intelligence (WISC), Imaton, St. Petersburg, 1994.

[17] Magomed-Eminov, M.S., Motivation and action control, MSU, Moscow, 1991.

[18] Druzhinin, V.N., Cognitive abilities: structure, diagnosis, and development, PER SE, Moscow, 2001.

[19] Burlachuk, L.F., Bleicher, V.M., Psychological diagnostic of intelligence and personality, Vishaya Shcola, Kiev, 1978.

[20] McClelland, D.C., Studies in Motivation, APPLETON-CENTURY-CROFTS, INC., New York, 1955. 